\title{
Research Compliance Challenges
}

\author{
Robert D. Hall
}

Associate Vice Provost for Research

University of Missouri-Columbia

\begin{abstract}
7 ompliance with an increasing number of federal and, to a lesser extent, state laws and regulations is a significant issue for all major research institutions. It consumes resources today at an increasing rate and burdens investigators with administrative requirements that compete with their academic pursuits. Areas where compliance issues are currently significant include human subjects research, research involving animals, conflict-of-interest, research integrity, and related research areas such as biological safety and export controls. All of these compliance areas serve as resource-allocation challenges for research administrators seeking to maximize the total campus impact of increasingly-scarce funding. Further, they exist to foster the public policy of conducting research in a safe and ethical manner.
\end{abstract}

Human subjects research, review by Institutional Review Boards (IRBs), and potential federal sanctions have been front-page news for the past five or six years. Most institutions seeking federal funding have augmented their human research protection programs, often at the expense of other priorities. At the University of Missouri-Columbia (MU), we have gone from two part-time IRB administrators to ten full-time personnel supporting our two boards. Still, we need additional staff if we are to respond successfully to the major issue considered critical by our investigator population: time-to-approval of protocols. To complicate matters, we are currently engaged in IRB accreditation through the Association for Accreditation of Human Research Protection Programs (AAHRPP). Our involvement in the accreditation process at this point is a byproduct of our affiliation with a collocated Veterans Administration hospital, but we hope that the expense and time expended in accreditation will eventually be worth the investment. On the health-sciences side of the house, we desperately need additional attention to billing compliance and audits of clinical trials-both areas fraught with the opportunity for regulatory disaster. One point of continuing investigator anxiety is that of training. We continually refine our on-line web sites and training modules to reflect the reality that scientists and faculty in general don't like to be "tested."

Animal use in research presents another fiscal challenge that daily confronts MU's research administration. A recent review by an external panel 
demonstrated that MU has (in 2003 dollars) about $\$ 97$ million in researchanimal infrastructure needs. Coupled with an estimated $\$ 70$ million in plantgrowth-facility needs, this represents a major fiscal hurdle for the campus. In addition, we have had to deal with startup costs for our Life Sciences Center vivarium as well as funding service-andmaintenance contracts for the equipment therein. Similar to human protection program accreditation, the Association for Assessment and Accreditation of Laboratory Animal Care, International (AAALAC) provides accreditation for MU's animal research facilities, except for those in the College of Agriculture, Food and Natural Resources (CAFNR). Bringing CAFNR under the AAALAC umbrella has generated much consternation regarding potential costs and benefits. In addition, per diem charges and electronic veterinary medical records are two areas where much effort recently has been expended, as it has been on the issue of investigator training in both basic animal-care as well as specialty areas. Presently, MU invests considerable staff time and effort in selfdisclosing animal-care compliance issues to DHHS's Office of Laboratory Animal Welfare. Of perhaps greater concern is administration of our Occupational Health-and-Safety Program for research animal workers. Mandated by our Collected Rules and Regulations (CRRs), enrollment in the program is required for MU employees and students, but the university's role is less clear in regard to non-MU employees (such as federal scientists and technicians) conducting research on campus under a variety of memoranda-of-understanding.
Conflicts-of-interest have raised compliance antennae nationwide over the past several years, especially as an offshoot of well-publicized controversy at the National Institutes of Health. MU currently has two conflict-of-interest policies in its CRRs: one is a "general" statement most directly applicable to individual financial conflicts in the typical business context, and the other resulted from the mid-'90s mandate that PHS or NSF grantee institutions maintain an appropriate written and enforced policy on conflict of interest consistent with provisions in 42 CFR Part 50 and 45 CFR Part 94 and the NSF Grant Policy Manual. The existence of these two policies has produced an interesting result, in that the aforementioned "general" policy proscribes MU employees using their university status in engineering contracts with outside business entities in which such employees have a "direct or indirect financial interest." This "direct or indirect" threshold has been interpreted to apply also in the context of research grants. It is the federal de minimus standards which appear in the second policy and on MU's grant-data form, and thus investigators who may in fact have a "direct or indirect" financial interest that does not exceed $\$ 10,000$ per annum or five percent equity may fail to disclose and thus be out of compliance with the general policy. Readers whose campuses are members of multi-campus university systems will appreciate the cumbersome nature of getting such policies revised. In addition, neither policy addresses the issue of institutional conflict-of-interest, which failing will become apparent as MU's IRBs move forward toward 
AAHRPP accreditation. Our campus Conflict-of-Interest Committee coordinates well with our IRBs because the IRB compliance officers sit as ex officio members on the former committee. A challenge remaining for this committee is effective annual review and audit of those management plans it has required.

Research integrity remains bright on the radar screens of university research compliance officers. As expected, the federal Office of Research Integrity within DHHS has recently promulgated both amended definitions of scientific misconduct and a revised policy for responding to allegations of research dishonesty. The University of Missouri policy has in turn been revised and the draft submitted for review, comment and action by System officials. Further concerns focus on the currentlysuspended Responsible Conduct of Research (RCR) initiative from DHHS and how much faculty time eventually will be absorbed both presenting and taking the required courses of instruction. A recent report ${ }^{1}$ suggests that the amount of research misconduct actually occurring at U.S. universities may be underestimated, supporting the ongoing educational efforts focused on RCR.

Related compliance areas currently taking considerable MU time and resources include biological safety and the Institutional Biosafety Committee (IBC). Recent federal guidance indicates that all recombinant-DNA research proposals should be reviewed at a convened IBC meeting, and further that

\footnotetext{
${ }^{1}$ Martinson, B.C., M.S. Anderson \& R. de Vries. 2005. Scientists behaving badly. Nature 435: 73738.
}

such meetings should be open to the public when practicable. Similar compliance committee meetings have not traditionally been open to the public, nor have their minutes been accessible via state open-records law. The USA Patriot Act appears to have sufficient congressional support to continue generally un-amended; thus, rules applying to Select Agents will remain a part of research compliance into the foreseeable future.

At $\mathrm{MU}$, we are fortunate to be home to the nation's most powerful research reactor, with the attendant radiation safety and Nuclear Regulatory Commission issues. Our Radiation Safety Committee constantly engages in oversight of radioactive isotopes on campus. Hazardous materials management is a collateral area that requires constant attention, and MU's Office of Research partners with the campus office of Environmental Health \& Safety in managing biosafety, radiation safety, and hazardous materials handling.

Export controls loom as the single regulatory issue in university research compliance with the potential for significant resource allocation in the immediate future. Although current export control regulations have been in place for many years, universities have traditionally relied on what is known as the "fundamental research exclusion" to exempt the majority of research projects from Department of Commerce licensing requirements. In fact, a quick review of existing export control regulations reveals that these are complicated rules administered by three major federal departments: Commerce, State and Treasury. Whereas patently military 
technology, governed by Department of State through International Traffic in Arms Regulations (ITAR), is generally easily recognized, the so-called "deemed export" rules of the Export Administration Regulations (EAR) administered by the Department of Commerce are in practice much more difficult to apply. "Dual use" technology appearing on the Commerce Control List (CCL) implicates an appropriate license when such technology is even discussed with a non-U.S. citizen or nonpermanent-resident from any of the countries listed on the Commerce Country Chart, unless such interaction occurs as part of fundamental research that is currently excluded under National Security Decision Directive 189. To date, universities have focused on those actions that will preserve their excluded status, such as refusing to accept restrictions on publications, refusing to accept restrictions on access by foreign nationals, and so forth. However, Commerce recently completed the noticeand-comment portion of a proposed rulemaking that would change the definition of equipment "use" and require as well that the country of birth be used to evaluate the license requirement on the Commerce Country Chart, rather than the country from which an individual emigrated to the United States. Compliance with existing export control requirements will require reallocation of existing administrative staff by almost all research institutions; compliance with the proposed changes, should they be implemented, will require a significant investment in additional staff. Similar changes to contractual language have recently been proposed by the Department of Defense. Not yet discussed in most national educational media is the provision of "services" to foreign nationals from those countries listed by the Office of Foreign Assets Control in the Department of Treasury.

Coming hard on the heels of recent compliance challenges in human subjects oversight, research animal welfare, and biologicals under the Patriot and Bioterrorism acts, the potential for additional staff in any administrative compliance function will be hard to justify to hard-pressed senior administrators. At MU, our system-wide leadership has called for a reduction in administrative positions, and so it is unlikely that we will be able to add significant staff absent some sort of emergent situation. However, that prospect does raise an important public policy question: "Where will the institution get the wherewithal to meet these significant new compliance challenges?" At MU, the recurring rate budget needs of compliance compete directly with needs for recurring faculty rate, although many of the most significant compliance issues relate primarily to the institution's research function. It is further a fact of life at our institution that we have long since exceeded the $26 \%$ administrative cap on facilities and administrative (F\&A) costs: MU's actual costs in this category currently exceed $32 \%$. One option might be to suggest again that the federal government acquiesce to increasing the administrative cap. Using current MU fiscal data, an increase of $1.5 \%$ (to $27.5 \%$ of the negotiated rate) would result in recovering an additional $\$ 500,000$ per annum, based on MU's actual recovery of 
F\&A (which currently hovers at about $18 \%$ ). As an aside, increasing total recovery of F\&A has been extremely problematic for our institution, given our Another option would be to campaign for line-item compliance amounts in the budgets of sponsored activities. One problem is that this puts the fiscal burden for compliance largely on activities that enjoy extramural sponsorship. Finally, requests for federal "handouts" have often been discussed at meetings where compliance budget challenges are discussed.

A frequently-unappreciated portion of compliance costs consists of faculty and staff time. In fact, a recent study of IRB-related expenses ${ }^{2}$ factored in what all administrators know is the most expensive aspect of faculty-populated committees: the professional time of those committee members who could be pursuing scholarship or interacting with students instead. Indeed, the issue of how much committee service is "too much" led most institutions to vest their IRBs with Health Insurance Portability and Accountability Act (HIPAA) compliance functions rather than to form a "privacy committee," which would have constituted one more entity requiring the input of faculty time. At MU, we are

\footnotetext{
${ }^{2}$ American Health Consultants. 2005. IRB costs are greater than previous estimates. IRB Advisor 5:77-78 (July).
}

land-grant status and the fact that we conduct significant state-supported research where rates of "indirect" are much lower than the federal level. currently developing comprehensive business plans for human subjects protections, animal care-and-use, and other compliance activities so that we can provide an accurate assessment of actual costs involved. Because we are dealing with a capped situation, even seemingly innocuous suggestions can have adverse fiscal consequences. As an example, a UM System committee recently required that all IRB records related to "medically invasive research" be archived for a period of ten years after research subjects reach age 21 . Thus, for research involving newborns, the archival period could be up to 31 years. The fact is that there are no funds in our IRBs' budgets to support this storage of records, even in electronic format, for this lengthy period of time.

Fielding an effective compliance effort is obviously one of the major costs associated with running an ambitious institutional research program. The reality that most compliance upgrades have come only after catastrophic problems should not deter research officers from working aggressively to ensure that appropriate resources are allocated to compliance oversight in all areas. Public policy demands no less. 